\title{
Análise do Programa de Desenvolvimento do Turismo do Nordeste (Prodetur/NE) na perspectiva do planejamento estratégico*
}

\author{
Maria das Graças de Menezes Venâncio Paiva**
}

Sumário: 1. Introdução; 2. Considerações teóricas; 3. Fases do crescimento do turismo nordestino anteriores ao Prodetur/NE; 4. O Programa de Desenvolvimento do Turismo (Prodetur/NE); 5. Considerações finais.

Summary: 1. Introduction; 2. Theoretical remarks; 3. Growth stages of the Northeastern tourism prior to Prodetur/NE ; 4. The Northeastern Tourism Development Program (Pordetur/NE); 5. Final remarks.

Palavras-chave: turismo; planejamento participativo e estratégico; parceria e rede de alianças; globalização.

KEY WORDS: tourism; participatory and strategic planning; partnership and alliance network; globalization,

Este artigo analisa o Programa de Desenvolvimento do Turismo no Nordeste (Prodetur/NE). A análise será feita dentro de uma perspectiva crítica que busca entender sua estrutura de gerenciamento. O programa é baseado em uma abordagem de autossustentabilidade e num moderno gerenciamento que supõe planejamento participativo e estratégico envolvendo parceria e ampla rede a alianças. Somente um elevado grau de consciência entre os vários atores nordestinos poderá garantir o sucesso do programa, o que implica consciência de todos eles em relação à interdependência entre os governos federal, estadual e municipal, bem com o empresariado e as organizações não governamentais (ONGs).

\footnotetext{
* Artigo recebido em maio 2009 e aceito em dez. 2009.

** Mestre em administração pela Escola Brasileira de Administração Pública (Ebape/FGV) e especialista em turismo. Professora aposentada a Universidade Federal do Rio Grande do Norte - Departamento de Ciências Administrativas. Consultora autônoma. Endereço: Rua Seridó, 755, apto. 801 — Petrópolis — CEP 59020-010, Natal, RN, Brasil. E-mail: gracave@yahoo.com.br.
} 


\begin{abstract}
Analysis of the Tourism Development Program (Pordetur/NE)
This article analyzes the Northeastern Tourism Development Program (Prodetur/ $\mathrm{NE}$ ) through a critical perspective seeking to understand its management structure. The program is based on a self-sustainability and modern management approach which assumes participatory and strategic planning involving partnership and a wide alliance network. Only a great dealof consciousness by the different Northeastern actors can guarantee the success of the program. All must be aware of the interdependence between federal, state and local governments, as well as businessmen and non-governmental organizations (NGOs).
\end{abstract}

\title{
1. Introdução
}

Este artigo analisa o Programa de Desenvolvimento do Turismo no Nordeste (Prodetur/NE), dentro de uma perspectiva crítica que busca entender sua estrutura de gerenciamento.

O programa analisado se projeta como um megaprojeto de investimentos adequado a um ambiente competitivo, em que os investimentos são internacionalizados - não somente os públicos, mas os privados a partir da integração do Banco Interamericano de Desenvolvimento (BID), que participa deles ao lado do Banco do Nordeste (BNB), seu órgão executor. O programa é baseado em uma abordagem de autossustentabilidade e num moderno gerenciamento que supõe planejamento participativo e estratégico. Entende-se que somente a consciência das condições de interdependência entre governo federal, governos estaduais e municipais, capital internacional, empresas e organizações não-governamentais (ONGs) torna possível a percepção por parte dos vários atores do processo que ora prevalece no turismo nordestino. Por sua vez, a estrutura de gerenciamento adotada vem atender a demandas sociais, o que requer mecanismos participativos e de gestão das políticas urbanas, considerando que o programa ora analisado se caracteriza como tal.

A proposta deste artigo é contribuir com a compreensão da sua gestão e o enfrentamento das dificuldades de modo mais fortalecido.

Para analisar o programa foram utilizadas como fontes de dados secundários jornais e revistas, documentos, internet, outros estudos e, como fonte de dados primários, entrevistas com alguns dos atores ligados ao seu gerenciamento.

Para realização da análise, alguns aspectos foram merecedores de atenção:

v a fundamentação do programa em desenvolvimento sustentável;

v o caráter das negociações; 
$\checkmark$ a internacionalização da rede hoteleira;

- a operacionalização do programa com base no planejamento estratégico, permitindo detectar ameaças como regiões competidoras em termos turísticos, com destaque para o Caribe, e as possibilidades nordestinas, como as peculiaridades das atrações naturais e das manifestações culturais da região;

v a sistematização das decisões referentes a projetos e ações seguindo uma agenda regional;

v a identificação dos mercados a serem atingidos com base em critérios racionais;

- a articulação dos estados e das organizações e/ou instituições participantes em redes;

v a integração das populações por meio de mecanismos participativos.

\section{Considerações teóricas}

\section{Sobre planejamento estratégico}

Há uma tendência na atualidade de se adotar o planejamento estratégico nas esferas pública e privada, supondo-se ser esse o instrumento mais adequado às necessárias parcerias, participações em redes e estabelecimento de alianças estratégicas próprias de um ambiente extremamente competitivo e mutável que emerge com a globalização.

O planejamento estratégico é a resposta a um ambiente competitivo em constantes mudanças, o que requer que sejam continuamente revistas a formulação e avaliação dos objetivos, fundamentadas num fluxo de informações sistemáticas sobre as transações entre o ambiente e a organização (Motta, 1996).

O uso do planejamento estratégico requer a visão mais ampla dos atores envolvidos e introduz o uso de novos métodos analíticos e prospectivos quanto à definição de cenários alternativos.

Portanto, o planejamento estratégico exige mudança bastante significativa na filosofia e nas práticas gerenciais.

Quanto ao planejamento participativo, ele se firmou no processo democrático na esfera das organizações, envolvendo as representações dos atores envolvidos com a formulação e implementação de um programa ou ação com repercussões na vida de comunidades e cidadãos. 
É um fato que a análise do ambiente externo permite construir cenários futuros alternativos possíveis de ocorrer com a identificação de oportunidades (Daft, 2007).

Daft afirma que diante da incerteza ambiental os tomadores de decisões não dispõem de informações suficientes sobre os fatores ambientais e assim encontram dificuldades na previsão das mudanças externas.

Todos os elementos que existem fora da organização e podem afetá-la constituem o ambiente organizacional. Pode-se destacar o ambiente de tarefas, que abrange diversos setores que afetam a organização.

Estabelecendo um paralelo com o turismo do Nordeste, pode-se situar algumas constatações:

v o setor de recursos humanos - novos postos de trabalho, modificações no mercado de trabalho e surgimento das escolas de treinamento especializadas, como o Hotel Escola Barreira Roxa, localizado em Natal, e o Serviço Nacional de Aprendizagem Comercial (Senac), que procuram atender com mais eficácia as novas demandas;

- o setor de recursos financeiros (BNB e BID), que atuam com programas como o Nordeste Competitivo e outros agentes financeiros, além dos investidores privados;

v o setor de mercado, abrangendo os consumidores reais e potenciais, domiciliados no Brasil e no exterior;

v o setor de tecnologia, desde o comércio eletrônico até as novas tecnologias hoteleiras;

- o setor de condições econômicas, compreendendo os indicadores específicos do turismo, como baixas e altas temporadas, taxas de inflação e câmbio, entre outros;

- o setor governamental, abarcando as conexões decorrentes da parceria público versus privado, ou seja, entre organizações públicas, inclusive jurídicas e privadas, que requerem regulamentações federais, estaduais e municipais e legislação ambiental;

- o setor sociocultural, abrangendo a biodiversidade cultural e a valorização das manifestações culturais mais autênticas da região, tais quais a música, a dança, o teatro e as artes plásticas e visuais, além do artesanato;

$\checkmark$ o setor internacional, considerando a concorrência de outros núcleos receptores de turistas, abertura de mercado em outros países ainda não trabalha- 
dos em termos mercadológicos, regulamentações, costumes estrangeiros e taxas de câmbio;

v o setor governamental, abrangendo legislações ambientais;

v o setor sociocultural — mudanças demográficas, migrações etc.;

v o setor de tecnologia - sites e internet, facilitando o gerenciamento do programa;

- recursos financeiros - determinantes na definição de ações e projetos.

Em relação ao ambiente externo, destaca-se a constância com que tem sido solicitado ao Ministério Público se manifestar quanto a questões de ocupação e uso do solo, casos de violência quanto a estrangeiros, permanência de estrangeiros, prazos legais, entre outros.

\section{Sobre política urbana}

Lojikne (1981:180-181) considera que a política urbana envolve três dimensões:

v planificadora - o documento da proposta de intervenção;

- operacional - práticas reais jurídicas e financeiras adotadas pelo Estado quanto à organização do urbano;

v urbanística - que verifica os efeitos sociais da planificação versus operação de urbanismo.

Para compreensão do Prodetur/NE como política urbana, tomou-se por base o método sugerido por Camargo, Lamparelli e George (1983:24), que aponta três vias de análise:

- base física - corresponde à localização dos equipamentos, à questão da terra urbana e interesses em jogo, até a produção e utilização dos equipamentos, desenhos e implantação das instalações, incluindo a tecnologia inerente ao processo de produção e financiamento físico do meio;

v operação - corresponde à estrutura administrativa, inclusive as contradições relativas à gestão do meio e formas como são resolvidos os diversos interesses;

v apropriação - compreende o consumo dos usuários, estruturados em classes e influenciadores das práticas de consumo. 


\section{Fases do crescimento do turismo nordestino anteriores ao Prodetur/NE}

Analisar o crescimento do turismo no Nordeste remete a diferentes etapas que refletem formas de atuação do Estado, como planejador e, mais recentemente, gerenciador e empreendedor dos chamados megaprojetos turísticos, culminando com a formulação do Prodetur/NE:

a primeira vai desde a criação da Comissão de Turismo Integrado do Nordeste/CTI/NE e das primeiras ações das agências governamentais regionais - BNB e Superintendência de Desenvolvimento do Nordeste (Sudene) até o II Plano de Desenvolvimento (II PND), que estabelecia como diretriz a valorização da orla marítima e do patrimônio histórico cultural, elegendo o turismo como uma estratégia de desenvolvimento econômico regional;

o segundo momento correspondeu à emergência do que se denominou "planos urbanístico-turísticos", ou seja, houve a determinação de formular e implementar planos turísticos em todo o litoral nordestino com a finalidade de implantar equipamentos turísticos e de consumo coletivo, combinados ou não a espaços para uso residencial;

จ na terceira fase, o turismo nordestino é impactado pelo processo de globalização em curso no mundo, trazendo inovações com a associação ao desenvolvimento autossustentável, ao apelo ecológico e cultural, variáveis relevantes para as agências transnacionais, detentoras de poder não somente de influenciar políticas destinadas ao setor, mas na dinâmica dos direcionamentos dos fluxos dos viajantes (Paiva, 1998:46).

\section{O Programa de Desenvolvimento do Turismo do Nordeste (Prodetur/NE)}

A região nordestina como espaço turístico foi se firmando durante anos devido a características ambientais favoráveis: litoral, clima, praias, vegetação, além das condições instigantes de alguns acontecimentos históricos, que deixaram relevantes marcos no seu patrimônio histórico e arquitetônico. Acrescenta-se a tais atrativos as manifestações culturais que mesclam as influências das etnias mais preponderantes na formação do povo nordestino, bem como a hospitalidade dos seus habitantes.

O alcance da mundialização nos negócios do turismo na região Nordeste não se dá apenas na fusão entre grupos — parcerias e acordos com grupos 
estrangeiros e/ou expansão das redes hoteleiras já existentes —, mas no interesse de agências internacionais de financiamento, além da inclusão de suas capitais e algumas das suas cidades nos roteiros regulares e voos especiais internacionais (os charters).

Sobre o impacto da globalização no turismo nordestino, Benevides (1998:327) destaca a ocorrência de alguns eventos:

$\checkmark$ o modo de financiamento e das operações dos equipamentos de hotelaria, adotando uma base tecnológica que segue padrões globais hegemônicos;

v a entrada das redes hoteleiras que operam em escala mundial, antes mesmo da implementação do programa;

v o discurso da conservação ambiental, considerado expressão do capitalismo tardio;

- a "turistificação" nordestina preconizada pelo megaprojeto analisado, inspirando-se e acompanhando experiências internacionais e modelos de urbanização turística do litoral;

v a perspectiva de captar demandas internacionais de turistas;

v a ação do agente financeiro internacional personificado pelo BID.

Como foi mencionado, antecedeu a implementação do programa analisado a política dos chamados "planos urbanísticos turísticos", que tinha como característica principal a participação do poder público, desde a concepção até os incentivos financeiros aos empreendimentos, diferentemente de outros projetos implantados no litoral brasileiro, localizados notadamente no centrosul, que foram capitaneados pela iniciativa privada.

Nessa perspectiva, os projetos mais representativos na região foram: o Linha Verde (Bahia), Cabo Branco (Paraíba), Costa Dourada (Pernambuco e Alagoas) e o Parque das Dunas - Via Costeira (Rio Grande do Norte). Tais projetos configuraram um modelo de urbanização que atendia aos seguintes aspectos:

v uma rodovia litorânea constituía o eixo aglutinador das zonas turísticas e de preservação;

- os governos se posicionavam como principais empreendedores e patrocinadores por meio de incentivos fiscais e financeiros;

v a ampliação da infraestrutura hoteleira era o principal objetivo perseguido;

v as zonas de preservação ambiental propiciavam a legitimidade à medida que recebiam o respaldo político necessário e o reconhecimento das comunidades. 
Sobre os planos urbanísticos turísticos, Paiva e Solino afirmam ser estes propostas de ocupação do espaço urbano que se baseiam na abertura de vias de acesso (estradas), ao longo do litoral, definição de áreas ou zonas com várias destinações e implantação de equipamentos de uso coletivo, destinados ao lazer e ao turismo, notadamente hotéis e/ou outros complexos de hospedagem (Paiva e Solino, 1997:337).

O Prodetur/NE não desconsidera os planos urbanístico-turísticos, no entanto, diferentemente dos mesmos, desde o início - primeira fase - conseguiu mobilizar capital internacional, tanto no aporte de recursos que o viabiliza quanto no que se refere à captação de investidores estrangeiros.

A dimensão operacional do programa abrange quatro macroestratégias: a) a captação de agentes imobiliários internacionais; b) a necessidade de manter fluxos de viajantes estrangeiros que garantam a ocupação; c) desfrute da infraestrutura turística disponível; e a estratégia de melhoria da infraestrutura urbana das cidades beneficiadas (rodovias, saneamento ambiental e embelezamento urbano).

A Fundação Empresa Brasileira de Turismo (Embratur), o Serviço de Apoio às Pequenas e Microempresas (Sebrae) - nacional e estaduais -, governos federal, estaduais e municipais e CTI/N realizam um trabalho de captação de investimentos por meio das bolsas, paralelamente à promoção de regiões e/ou localizações de extremo valor paisagístico.

O programa na sua primeira fase, mais conhecida como Prodetur/NE I, iniciado em 1994, tinha como objetivo criar condições favoráveis à expansão e melhoria da qualidade da atividade turística e melhoria da qualidade de vida das populações dos municípios alcançados. $\mathrm{O}$ aporte de recursos de investimentos totalizou US\$ 670 milhões.

Na fase I foram privilegiadas: a infraestrutura de saneamento básico (água e esgoto) e de suporte ao turismo - instalação ou ampliação de aeroportos, urbanização de áreas turísticas, centro de convenções, recuperação do patrimônio histórico, bem como um aquecimento da economia das localidades turísticas.

Os resultados satisfatórios do Prodetur I e o cenário de sucesso motivaram a concepção do Prodetur II. As negociações iniciadas em 1999 foram sucedidas por estratégias mais racionais em substituição às anteriores, que muitas vezes se baseavam em tentativas de acerto e erro. Para a continuidade do programa foram disponibilizados US\$ 800 milhões.

Obras infraestruturais, saneamento, transportes, urbanização, proteção ambiental e do patrimônio histórico e cultural, projetos de capacitação profissional e fortalecimento institucional dos estados e municípios são metas a serem alcançadas. 
A grande inovação na segunda fase é a definição de polos turísticos e a ampliação do seu raio de ação, ao serem incluídos os estados de Espírito Santo e Minas Gerais, este último integrante da zona conhecida como Polígono das Secas da região nordestina.

Assim, foram definidos os seguintes polos: São Luís (Maranhão), Costa do Delta (Piauí), Costa do Sol (Ceará), Costa das Dunas (Rio Grande do Norte), Costa das Piscinas (Paraíba), Costa dos Arrecifes (Pernambuco), Costa dos Coqueirais (Sergipe), Salvador e Entorno (Bahia), Litoral Sul (Bahia), Costa do Descobrimento (Bahia), Vale Mineiro do São Francisco (Minas Gerais), Vale do Jequitinhonha (Minas Gerais) e Costa do Marlin (Espírito Santo).

Posteriormente, cada estado estabeleceu ou não novos polos. É exemplar o caso do Rio Grande do Norte que, além do Polo Costa das Dunas, trabalha atualmente os polos do Seridó e Costa Branca.

Constitui objetivo geral do megaprojeto, na segunda etapa, a melhoria da qualidade de vida da população que reside nos polos turísticos situados nos estados participantes. São objetivos específicos:

v promover o aumento das receitas provenientes das atividades turísticas;

v melhorar a capacidade de gestão dessas receitas por parte dos estados e municípios;

v assegurar o desenvolvimento turístico autossustentável e responsável nas áreas beneficiadas pelo programa;

v melhorar a qualidade de vida das populações nos municípios;

- conferir a sustentabilidade às ações realizadas no âmbito da primeira fase do programa, antes de expandir a atuação para novas áreas turísticas.

No final dos anos 2000 o grau de complexidade do programa é bem maior. Cabe a cada polo turístico elaborar um Plano de Desenvolvimento Integrado do Turismo Sustentável (PDITS), que é avaliado pelo Ministério do Turismo (MTur).

Como estratégias salientam-se:

- definição de áreas a serem beneficiadas pelas ações do programa com base no conceito de polos turísticos - espaços geográficos com vocação acentuada para o turismo;

v realização de planejamento participativo, integrado e sustentável para o desenvolvimento do turismo nos polos selecionados; 
V foco em ações visando beneficiar as populações locais;

$\checkmark$ priorização de ações que visem à integração de passivos ambientais, associados a alguns dos projetos do programa;

v priorização de ações necessárias para completar os investimentos da primeira fase do programa;

$\checkmark$ fortalecimento da gestão ambiental.

O programa mobiliza o esforço de uma matriz de relacionamento, da qual fazem parte o BID e o BNB, o Banco Nacional de Desenvolvimento Econômico e Social (BNDES), a Embratur, o MTur, a Infraero, a CTI/NE, os estados e municípios, por meio das secretarias estaduais e municipais de turismo, e as unidades executoras dos estados e municípios (UEE e UEM).

São componentes do Prodetur II:

v fortalecimento da capacidade municipal e gestão do turismo;

v planejamento estratégico, treinamento e infraestrutura para o crescimento;

v promoção de investimento do setor privado.

Com base no planejamento estratégico, os recursos do programa devem contemplar: consultoria, capacitação, sistemas e equipamentos de informática, material de apoio e instalações físicas.

O fortalecimento institucional deve resultar na eficácia da gestão do turismo; ampliação da participação da sociedade no controle social; redução dos impactos negativos das atividades turísticas; e melhoria no atendimento.

Cabe às secretarias estaduais de turismo desenvolver ações no sentido de valorizar pessoal por meio de capacitações; fomentar o desenvolvimento do turismo sustentável; incentivar a participação da sociedade através de mecanismo de controle social; promover a articulação das ações; e melhorar o atendimento aos turistas.

O programa esbarra em entraves ao propor conceitos ainda não familiarizados pelos atores envolvidos, tais como planejamento participativo ou desenvolvimento sustentável, mas funciona como uma grande oficina de aprendizagem.

No ambiente externo, dificuldades próprias da dinâmica social e econômica. De um modo geral, como obstáculos ao programa foram consideradas: a recessão mundial que interfere nos fluxos de viajantes, a difícil disponibilidade de recursos públicos e privados para investimentos, as precárias condições de utilização do solo, a inexistência e/ou insuficiência da infraestrutura, a 
deficiência dos equipamentos e serviços, a falta de capacitação dos recursos humanos, a comercialização inadequada do chamado produto turístico e a ineficácia dos sistemas oficiais de turismo - secretarias e empresas de economia mista de turismo.

Estudos diagnósticos que precederam os planos estaduais apontavam como entrave a pouca capacidade do turismo de se articular a outras atividades econômicas e promover as comunidades situadas em seu entorno.

A atuação das instituições e dos estados envolvidos em rede favoreceu algumas ações e/ou impactos.

Vale o registro que foi implementado no início dos anos 1990, o Programa Nacional de Municipalização do Turismo (PNMT), capitaneado pela Embratur, que avançou quanto ao entendimento do planejamento físico-territorial, alguma noção de planejamento participativo, bem como na questão da cidadania e participação popular.

Na contemporaneidade, o Prodetur/NE tem por característica promover a articulação com programas desenvolvidos, como o Nordeste Competitivo do BNB, com ampla atuação na concessão de incentivos financeiros para os investimentos privados, e, mais recentemente, envolver o Programa de Aceleração do Crescimento (PAC).

\section{Metodologia de gerenciamento}

Como já foi afirmado, o Prodetur é implementado tendo como base o planejamento estratégico e participativo que se respalda em um esquema institucional fundamentado em mecanismos de participação direta.

Assim, a parceria entre o BID e o BNB favoreceu o programa por meio de recomendações técnicas com destaque para:

- divulgação das melhores práticas por meio de mecanismo de articulação e difusão das informações através de encontros sistemáticos para intercâmbio e troca de experiências;

v qualidade dos serviços contratados;

v economia de escala através da implantação de procedimentos centralizados;

- participação das populações por meio da implantação de metodologias participativas nas atividades de capacitação e consultoria, realização de pesquisas de opinião no envolvimento dos beneficiários na avaliação das ações;

v valorização dos recursos humanos. 
Atualmente identificam-se novos conceitos e estratégias que modificam o seu gerenciamento, ou seja, maior relevância da competência técnica e cooperação técnica entre as várias instituições que compõem a rede de gerenciamento.

Nos anos 1990, as leis orgânicas e os planos diretores institucionais facilitaram a gestão municipal das políticas urbanas, caracterizando novas formas de gerenciar e controlar as tais políticas, que puderam ser acompanhadas pelas populações, sendo estimulado o controle social delas.

Foram adotadas formas de participação direta da sociedade civil através dos conselhos gestores e do orçamento participativo. Por sua vez, a cidadania ampliada visa trazer para a política os interessados em reorganizar os espaços e, pouco a pouco, superar as desigualdades sociais.

Para atender ao gerenciamento do programa analisado, a condição do BID e do BNB era que cada estado nordestino implantasse uma unidade executora estadual (UEE), a qual caberia elaborar e acompanhar projetos e ações relativas ao programa. Outra condição colocada pelo BID e pelo BNB como essencial para a liberação dos recursos do programa consistiu no fortalecimento institucional.

Vários instrumentos de gerenciamento são utilizados para facilitar a maior integração com as comunidades beneficiadas, bem como para atender às avaliações das instituições envolvidas. São eles:

- os conselhos de turismo dos polos são espaços sistematizados para o planejamento, a deliberação e a viabilização de ações que concorram para o desenvolvimento do turismo, através da identificação de entraves existentes e implementação de soluções sistêmicas;

v agenda de compromissos que são instrumentos de registro dos compromissos firmados entre os parceiros envolvidos;

v site na internet;

v formação de multiplicadores estaduais do BNB;

v promoção de ações com vistas à atuação da iniciativa privada, complementando as ações do Prodetur I e integrando a cadeia produtiva do turismo do Nordeste, no âmbito de articulação do Plano de Aceleração do Crescimento (PAC).

A preocupação do BID e do BNB é com o fortalecimento, a preparação, o desenvolvimento e a execução dos próprios projetos de fortalecimento institucional. Essas instituições sugerem quatro áreas de atuação: estrutura- 
ção administrativa, gestão de recursos humanos, gestão estratégica e gestão operacional.

Os investimentos em relação ao gerenciamento devem contemplar consultoria, capacitação, sistemas e equipamentos de informática, material de apoio e comunicação e equipamentos de informática.

A orientação do BID e do BNB afeta toda a rede, abrangendo os programas estaduais e almeja os seguintes resultados:

v ampliação da eficiência na execução do programa;

$\checkmark$ ampliação da qualidade dos serviços prestados;

v melhoria dos instrumentos de gestão;

v aumento da transparência nas ações e nos resultados do programa.

Fleury e Fleury (2000) visualizam três níveis de competência nos indivíduos: a) competências de negócio relacionadas à compreensão do negócio, seus objetivos, cliente e competidores, bem como o ambiente político e social; b) competências técnico-profissionais - competências específicas para aquela operação; e c) competências sociais - competências necessárias para interagir com pessoas.

Entre as competências sociais, é relevante para o programa analisado a capacidade de comunicação, de negociação e de trabalho em equipe por parte dos técnicos envolvidos.

Quanto aos objetivos a serem alcançados, verifica-se que a grande tônica nos últimos anos de implementação do programa vem a ser a melhoria da infraestrutura urbana e turística e a captação de investimentos estrangeiros, o que tem desencadeado um processo de especulação imobiliária com ampla periferização das populações das comunidades afetadas, sem falar nos problemas sociais que estão sendo gerados.

Nesse caso, se aplica a necessária visão estratégica, que vai além da adoção de táticas que significam conhecer o negócio e os ambientes interno e externo, identificando oportunidades, ameaças, pontos fortes e fracos, mas com clareza quanto a objetivos e valores.

Em termos da ocupação do espaço, as modificações são bastante acentuadas. Números de 2008 identificam 42 resorts na região, com detaque para os seguintes: Salinas de Maragogi e Venta Club Pratigy (Alagoas); Arraial d'Ajuda, Eco Resort, Cana Brava, Catnossaba, Club Med Itaparica, Club Med Trancoso, Itacaré Eco Resort, Kiroa, Costa do Sauípe, Patachocas, Praia do Fort, Renaissance, Super Club, Tororomba, Hotel Transamérica e Txai Resort 
(Bahia); Hotel Oásis Atlântico, Beach Park e Vila Galé (Ceará); Eco Resort do Cabo, Summervile e Venta Club Porto de Galinhas (Pernambuco); e Pestana (Rio Grande do Norte).

Os resorts vêm sendo alvo de críticas, porque configuram verdadeiros enclaves, isolando seus hóspedes, e com atividades operacionais sem o consumo de produtos e gêneros alimentícios das comunidades em que estão localizados.

Em contraponto a essa lógica globalizada, proliferam pequenas e microempresas e algumas franquias, identificadas como atividades das comunidades solidárias (Coriolano, 1998).

No novo cenário emerge uma dinâmica complexa, que ainda não atingiu o nível de compreensão desejada. Trata-se da relação entre o crescimento do turismo nordestino com a valorização das terras e especulação imobiliária. As imobiliárias compram as terras e depois vendem para grupos de investidores internacionais, com estrangeiros já infiltrados no mercado imobiliário que executam todas as operações. Essas terras destinam-se não apenas à implantação de unidades hoteleiras, mas à segunda residência ou à primeira residência.

Os grupos estrangeiros associam-se também a grupos locais, compram ações e participam de fundos de investimentos.

Dependendo da localização, alguns empreendimentos oferecerão aos seus compradores a opção de primeira residência, contribuindo para tal a facilidade de acesso à BR-101, em obras de duplicação.

Enquanto a predominância como investidores, na época dos planos urbanísticos turísticos, era dos grupos locais e nacionais, no cenário contemporâneo, é acintosa a presença de redes estrangeiras.

\section{Algumas diferenças na implementação do Prodetur/NE nos estados}

Apesar das orientações proporem uma homogeneização das condutas nos vários estados da região, incentivando a articulação, a ênfase na qualidade dos serviços contratados e a participação das populações, entre outros, cada estado vem respondendo de maneira distinta aos apelos do programa, o que de certa maneira atende as suas peculiaridades e práticas de planejamento anteriormente adotadas.

Assim, a Bahia tem por referência um modelo de turismo sustentável que integra as esferas econômica, sociocultural e ambiental, fortalecendo a identidade que tem por base valores referenciais do seu povo. 
Naquele estado foram identificados roteiros com atrações e atrativos específicos. São eles: Lagos de São Francisco, Costa dos Coqueiros, Bahia de Todos os Santos, Costa do Dendê, Costa do Cacau, Costa do Descobrimento, Costa das Baleias, Caminhos do Oeste, Chapada da Diamantina e Vale do Jequiriçá.

O estado de Pernambuco formulou projetos e ações bem definidos e propôs uma plataforma exaustiva, que abrange desde melhorias urbanas, como tratamento de resíduos sólidos, ampliação do sistema de abastecimento de água, urbanização de áreas turísticas e elaboração de campanhas publicitárias, até o fortalecimento institucional, incluindo a capacitação de recursos humanos.

No Rio Grande do Norte uma avaliação realizada pelo BNB constatou aumento do fluxo turístico, do número de empregos diretos e da oferta de leitos, ampliação da receita em 56\%, de 1995 a 2001, do número de voos e da arrecadação dos municípios.

Entre as ações executadas no estado destacam-se a elaboração da base cartográfica do polo Costa das Dunas, a implantação do sistema de esgotamento sanitário das praias de Cotovelo e Pirangi, a correção de passivos ambientais de trechos rodoviários da rodovia Tibau do Sul-Pipa e a implantação da sinalização turística do polo Costa das Dunas.

Duas condições foram submetidas para a inclusão no programa e liberação dos recursos para realização da avaliação ambiental estratégica e a formação de conselhos.

É nesse novo momento que se instalam os complexos turísticos - alguns somente com hotéis e outros com áreas destinadas a segundas residências de estrangeiros ou mesmo a primeiras.

Um aspecto contraditório no Rio Grande do Norte é a fundamentação do programa em planejamento estratégico, enquanto o governo é acusado de não dispor de estratégias de enfrentamento das oscilações do mercado com a queda do movimento do fluxo de visitantes estrangeiros e a baixa ocupação da rede hoteleira, diante da competição feroz de outros destinos.

\section{Considerações finais}

Considera-se o Prodetur/NE inovador no que se refere tanto à sua concepção quanto à sua gestão. Ao ser formulado com base no planejamento estratégico ele consegue abranger todas as variáveis ambientais, tornando possível a integração de vários atores.

Para tanto, recorre a mecanismo de participação direta através de redes de parceiras, matriz de relacionamento, conselhos, seminários e campanhas 
de conscientização, inclusive das populações beneficiadas moradoras dos polos turísticos. Integram a rede diversas instituições, inclusive as financeiras, empresas privadas e ONGs.

O sistema de gerenciamento implantado é bastante moderno, favorecendo o empreendedorismo e a participação comunitária, além de ser extremamente abrangente, alcançando metas relacionadas ao meio ambiente, ao saneamento básico e à acessibilidade (rodovias).

O programa trouxe um impacto bastante positivo para as equipes técnicas envolvidas, exigindo mais conhecimento e competência técnica das mesmas, até porque envolve inovações na maneira de formular e implementar programas de governo.

O cenário atual é diferente e nele se delineia um campo de forças, com antigos e novos atores, que se mobilizam, como associações de moradores, Justiça, empresas incorporadoras, investidores internacionais e as populações que acompanham o processo pela imprensa ou pela internet.

Nesse movimento de fluxos de capital e nova configuração do turismo nordestino o "city-marketing tem um papel fundamental".

\section{Referências}

BAHIA. A nova estratégia 2003-2020. Século XXI: consolidação do turismo.

BENEVIDES, Ireleno Porto. Planejamento governamental do turismo meio ambiente construído e desenvolvimento do Nordeste. In: LIMA, Luiz Cruz (Org.). Da cidade ao campo: a diversidade do saber-fazer turístico. Fortaleza: Uece, 1998.

BID/BNB. Anexo II. Fortalecimento institucional das UEEs (Unidades Executoras Estaduais).

BID/BNB. Anexo $D$. Fortalecimento institucional dos órgãos gestores. Planejamento estratégico, treinamento e infraestrutura.

CAMARGO, Aziel R.; LAMPARELLI, Celso Monteiro; GEORGE, Pedro Silva. Nota introdutória sobre a construção de um objeto de estudo: o urbano. Estudos Fundap, n. 1, 1983.

COFIEX recomenda empréstimo do BID para o Prodetur/RN. Jornal de Hoje, 25 jul. 2008, p.4.

CORIOLANO, Luzia Neide M. T.; ALMEIDA, Humberto Marinho. O turismo no Nordeste brasileiro: dos resorts aos núcleos de economia solidária. Revista Eletrônica de Geografia e Ciências Sociais, Barcelona, v. 11, n. 245, ago. 2007. 
COSTA, Jean Henrique. O modelo de desenvolvimento do Prodetur.

DAFT, Richard. Teoria e projetos organizacionais. São Paulo: Thompson e Learning, 2007.

FLEURY, Afonso; FLEURY, Maria Tereza Leme. Estratégias empresariais e formação de competências: um quebra-cabeça caleidoscópico da indústria brasileira. São Paulo: Atlas, 2000.

IANNI, Otávio. Sociedade global. Rio de Janeiro: Civilização Brasileira, 1992. . O labirinto latino-americano. Petrópolis/RJ: Vozes, 1993.

LOJIKNE, Jean. O Estado capitalista e a questão urbana. São Paulo: Martins Fontes, 1981.

MERCADO para segunda residência se fortalece. Tribuna do Norte, 29 fev.2008, Economia, p. 6.

MOTTA. Gestão contemporânea. A ciência e a arte de ser dirigente. Rio de Janeiro: Record, 1996.

PAIVA, Maria das Graças de Menezes Venâncio. Inquietações sobre o turismo e o urbano na região Nordeste. In: Lima, Luiz Cruz (Org.). Da cidade ao campo: a diversidade do saber-fazer turístico. Fortaleza: Uece, 1998.

; SOLINO, Antonia da Silva. Tecnologia apropriada: possibilidades e questionamentos em torno dos planos urbanísticos turísticos no Nordeste. Revista Econômica do Nordeste, v. 2, n. 2, p. 337-361, abr./jun. de 1990.

QUEIROZ, Lucia Aquino. A evolução do sistema institucional do turismo bahiano. Análise de Dados, Salvador, v. 2, p.20-28.

TEMOS que captar novos "charters". Tribuna do Norte, 17 fev.2006, Economia, p.3.

TURISMO espera dias ruins para julho. Diário de Natal, 11 jul. 2008, Economia, p. 1. 